\title{
Dengue virus infection presenting with diffuse brain hemorrhage
}

Infecção pelo virus da dengue se apresentando com hemorragia cerebral difusa

Ricardo Tavares Daher ${ }^{1}$, Victor Hugo Rocha Marussi ${ }^{1}$, José Luiz Pedroso², Acary Souza Bulle Oliveira², Lázaro Luiz Faria do Amaral ${ }^{1}$

A 40-year-old woman presented to the emergency department with acute decreased level of consciousness, associated with respiratory failure. She has complained of headache, fever, myalgia and dyspnea for the last seven days. Neurological examination disclosed decreased level of consciousness. Brain CT scan disclosed multiple intracerebral acute hemorrhage lesions (Figure). After extensive investigation, serologic test confirmed Dengue virus infection.
Brain involvement in dengue virus infection may have variable presentation, and encephalitis is the most common $^{1-3}$. However, although unusual, patients may present with cerebral hemorrhage, particularly in hemorrhagic dengue ${ }^{4,5}$. Pathophysiology may include: capillary hemorrhage, disseminated intravascular coagulation and cerebral edema ${ }^{4}$.
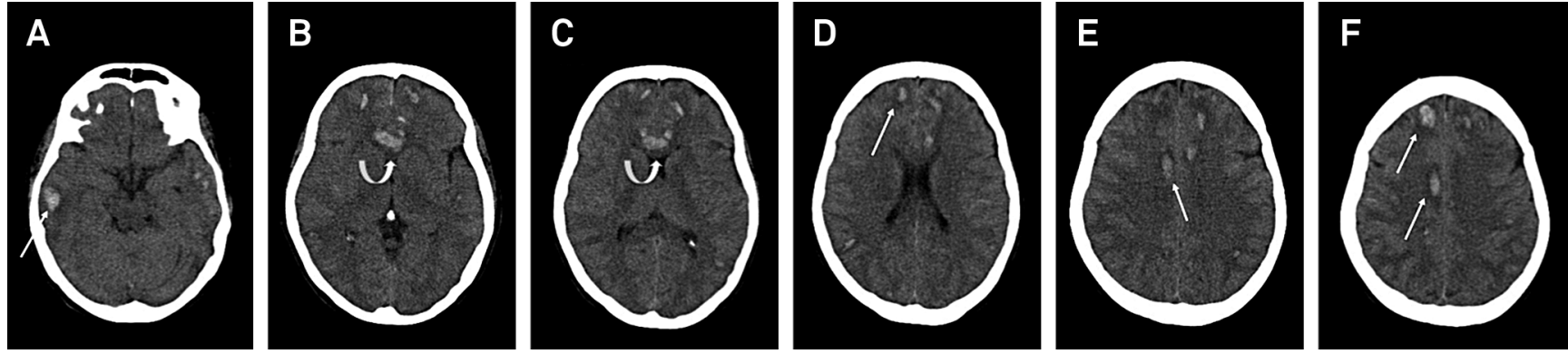

Figure. Axial brain CT scan discloses bilateral and asymmetrical subcortical (straight arrows) and pericallosal (curved arrows) hemorrhage predominant in frontal and temporal lobes.

\section{References}

\footnotetext{
1. Carod-Artal FJ, Wichmann O, Farrar J, Gascón J. Neurological complications of dengue infection. Lancet Neurol. 2013;12(9):906-19. http://dx.doi.org/10.1016/s1474-4422(13)70150-9

2. Puccioni-Sohler M, Rosadas C, Cabral-Castro MJ. Neurological complications in dengue infection: a review for clinical practice. Arq Neuropsiquiatr. 2013;71(9B):667-71. http://dx.doi.org/10.1590/0004$282 \times 20130147$

3. Gupta M, Nayak R, Khwaja GA, Chowdhury D. Acute disseminated encephalomyelitis associated with dengue infection: a case
}

report with literature review. J Neurol Sci. 2013;335(1-2):216-8. http://dx.doi.org/10.1016/j.jns.2013.08.029

4. Souza LJ, Martins AL, Paravidini PC, Nogueira RM, Gicovate Neto C, Bastos DA et al. Hemorrhagic encephalopathy in dengue shock syndrome: a case report. Braz J Infect Dis. 2005;9(3):257-61. http://dx.doi.org/10.1590/s1413-86702005000300009

5. Kumar R, Prakash O, Sharma BS. Dengue hemorrhagic fever: a rare presentation as atypical acute subdural hematoma. Pediatr Neurosurg. 2008;44(6):490-2. http://dx.doi.org/10.1159/000180305

${ }^{1}$ Med Imagem, Hospital Beneficência Portuguesa de São Paulo, Sao Paulo SP, Brazil;

${ }^{2}$ Departamento de Neurologia, Universidade Federal de São Paulo, Sao Paulo SP, Brazil.

Correspondence: Ricardo Tavares Daher, Hospital Beneficência Portuguesa de São Paulo; Rua Maestro Cardim, 968; 01323-001 São Paulo SP, Brasil; Email: ricardotdaher@hotmail.com

Conflict of interest: There is no conflict of interest to declare.

Received 13 May 2014; Received in final form 27 June 2014; Accepted 17 July 2014. 